\title{
Os animais e a construção identitária em Carlos Drummond de Andrade
}

Suellen Rodrigues Rubira*

\section{Resumo}

O presente ensaio aborda a representação animal como construção identitária na narrativa memorialística de Carlos Drummond de Andrade, a saber, a trilogia Boitempo. Composta pelos volumes Boitempo, Menino antigo e Esquecer para lembrar, a autobiografia do poeta acaba por subverter o gênero em questão ao propor uma narrativa em forma de poesia e, ainda, versar sobre uma personagem bastante conhecida, o gauche. Quanto à simbólica animal, é possível pensá-la em termos de bestiário, ou seja, um conjunto de animais que dá ao universo drummondiano uma coerência própria. O estudo dos poemas "Signo", "Aquele Andrade" e "Cheiro de couro", de Boitempo I, II e III, respectivamente, sintetiza o percurso de Drummond ao unir as pontas da literatura e da memória e, ainda, pensar o outro que é o animal.

Palavras-chave: Poesia brasileira contemporânea. Carlos Drummond de Andrade. Bestiário. Imaginário.

\section{Introdução}

Boitempo, Menino antigo e Esquecer para lembrar compõem a poética autobiográfica de Drummond, na qual acompanhamos a genealogia, o nascimento e o desenvolvimento do personagem gauche. Nas respectivas obras ecoam as vozes de um passado muito anterior: a paisagem, a vila, o sangue da família Andrade. Há, pois, uma (re)construção - da e pela memória - da cidade de Itabira pré-sujeito, das Minas Gerais, vivida e não vivida.

\footnotetext{
Doutora em Letras, área de concentração em História da Literatura, pela Universidade Federal do Rio Grande - FURG (2018), com período sanduíche na Universidade Nova de Lisboa (2015-2016). Mestre em História da Literatura, também pela Universidade Federal do Rio Grande - FURG (2014); ao longo do período que atuou na pós-graduação dedicou-se aos estudos da poesia de Carlos Drummond de Andrade, com base na filosofia do Imaginário. Graduada em Letras Português - Inglês e respectivas Literaturas, igualmente pela Universidade Federal do Rio Grande (2011), bolsista CNPq (20092012), realizando estudos nas áreas de periódicos lusitanos do século XIX. Atualmente, dedica-se ao estudo da filosofia do Imaginário relacionado à poesia de expressão feminina, especialmente a obra da Hilda Hilst. E-mail: suellen.rubira@yahoo.com.br
}

Data de submissão: 11 dez. 2019 - Data de aceite: 19 fev. 2020 http://dx.doi.org/10.5335/rdes.v16i1.10378 
Por outro lado, Drummond não nos conta sua vida somente nesses três livros, pois já em Alguma poesia (1930) ele trabalha imaginativamente o seu pretérito na matéria poética:

Meu pai montava a cavalo, ia para o campo. Minha mãe ficava sentada cosendo.

Meu irmão pequeno dormia.

Eu sozinho menino entre mangueiras

lia a história de Robinson Crusoé

(ANDRADE, 2015, p. 10).

O poeta recria seu universo, repleto de montanhas, pessoas ilustres e metais preciosos. Carlos - menino - conduz-nos à sua infância, suas alegrias, anseios e angústias até chegar à adolescência. Assim como as narrativas, de vida ou de ficção, sua poética pessoal não segue uma linearidade, construindo-se, portanto, de modo irregular. Os capítulos da trilogia Boitempo ilustram tal descontinuidade: "Notícias de clã" aparece no primeiro e no terceiro volumes, "O menino e os grandes" se repete em Boitempo II e III, interceptados por tantos outros temas nucleares em sua composição.

Chamo a atenção para uma simbologia recorrente em toda a obra de Drummond, a qual pode auxiliar na compreensão da formação de Carlos como poeta. Refiro-me às figuras de animais, companheiros permanentes do eu-lírico, que conduzem o menino até o estágio de poeta-homem, quem compreende sua história e sua origem para poder formular uma hipótese do que é ser, pois, humano.

\section{A especificidade do devaneio da infância}

Os poemas estudados neste ensaio abarcam o imaginário da infância e, para compreender esse imaginário singular, cabe comentar os postulados de Gaston Bachelard acerca do devaneio poético. Em sua obra sobre o tema, o filósofo francês busca, por meio do método fenomenológico, a imagem em sua gênese. Contrário às teorias psicanalíticas freudianas da linguagem como liberação de instintos recalcados, Bachelard crê na novidade da imagem, num porvir da linguagem. Por isso o interesse em sua origem:

Não se lê poesia pensando em outra coisa. Desde que uma imagem poética se renova, mesmo em um só de seus traços, manifesta uma ingenuidade primordial (BACHELARD, 2006, p. 04).

Bachelard procura a intencionalidade da imaginação, pois a postura fenomenológica não se coloca passivamente. Ao eleger o devaneio poético como seu objeto de estudo, o autor ressalta a diferença de abordagem nesse sentido. Enquanto a psicologia observa o ser que sonha, para a fenomenologia interessa $o$ ato de criação, no qual observamos a inovação da linguagem. Se os psicólogos buscam 
um passado, isto é, decifrar na vida do poeta caracteres estampados na sua obra, Bachelard postula o inverso: a imaginação é excitação de devir psíquico, "a imaginação tenta um futuro" (BACHELARD, 2006, p. 08). A preocupação do filósofo, nesse momento, é a de "indicar o caráter construtivo do devaneio poético" (BACHELARD, 2006, p. 10).

Em sua poética do devaneio, o filósofo francês dedica um capítulo ao tema da infância, no qual sublinha a necessidade de retorno à infância, entendida como um cosmos de solidão. Bachelard, ainda, argumenta que a retomada desse tempo particular é feita pelos poetas já em idade mais avançada, e esta - coincidentemente - é uma das características do gênero autobiográfico. ${ }^{1}$

A infância possui valor fundamental no resgate memorialístico de Drummond, uma vez que é a fase da vida mais narrada, considerando os temas centrais nas obras: anterioridade do ser (ou seja, remontando um passado no qual Carlos nem sequer havia nascido), infância e um pouco da mocidade. Alguns aspectos sobre o período de Carlos menino são chave para o entendimento das outras pontas de Boitempo e também de sua poética como um todo.

Em primeiro lugar, a grandeza do mundo na infância. Ao visitar seu passado infantil, Carlos perde-se na vastidão do espaço. A esse respeito, Bachelard afirma: "o mundo do devaneio de infância é grande, maior que o mundo oferecido ao devaneio de hoje" (BACHELARD, 2006, p. 96). Dessa forma, o "menino antigo" encontra-se em relação de desigualdade com o ambiente circundante, o pequeno encara o (mundo) grande.

Ademais, é importante considerar a estreita relação entre imagem e memória, as quais dão vida a esse tipo de devaneio poético. A imaginação, seletiva, sabe desde o princípio quais histórias contar. Todavia, a antecedência do ser atribui à infância um caráter cósmico. Esse aspecto é bastante recorrente na série Boitempo: Drummond se vê assombrado por sua árvore genealógica, pois ser um Andrade pesa sobre os ombros do menino, o qual vê - no ar - a sua fazenda, e rejeita a responsabilidade implícita de dar continuidade ao cuidado dos bois, cavalos e terras de seu pai. De acordo com Bachelard:

A cosmicidade de nossa infância reside em nós. Ela reaparece em nossos devaneios solitários. Esse núcleo de infância cósmica é então como uma falsa memória em nós. Nossos devaneios solitários são as atividades de uma metamnésia. Parece que os voltados para os devaneios de nossa infância nos fazem conhecer um ser anterior ao nosso ser, toda uma perspectiva de antecedência do ser (BACHELARD, 2006, p. 103).

Essa busca de um ser anterior mostra justamente o quanto um devaneio voltado para o ser da infância não está subordinado às regras temporais cronológicas e factuais. $\mathrm{O}$ período anterior ao nascimento é o "cosmos dos limbos" 
Tal constatação leva-nos ao terceiro ponto importante sobre esse devaneio primordial, o do elemento aquático como regente do devaneio:

Luzes e limbos, eis a dialética da antecedência do ser de infância. Um sonhador de palavras não pode deixar de mostrar-se sensível à doçura da palavra que põe luzes e limbos sob o império de duas labiadas. Com a luz, há a água na claridade e os Limbos são aquáticos. E sempre havemos de encontrar a mesma certeza onírica: a Infância é uma Água humana, uma água que brota da sombra. [...]. Então o devaneio voltado para o nosso passado, o devaneio que busca a infância, parece devolver vida a vidas que não aconteceram, vidas que foram imaginadas. O devaneio é uma mnemotécnica da imaginação. No devaneio retomamos contato com possibilidades que o destino não soube utilizar (BACHELARD, 2006, p. 106-107, grifo meu).

O devaneio, nesse sentido, não possui uma conexão direta com o fato ocorrido no passado, ele é a criação de uma percepção, um ponto de vista, um impulso criativo. Portanto, na série em questão, acompanhamos a gênese do gauche, pois é esse personagem quem atravessa a poética drummondiana. Por essa razão, Carlos, adulto, lança um olhar crítico ao menino, ou então, vive sua segunda infância, muito mais consciente dos seus atos e dos outros do que quando na infância "real". A nostalgia do poeta sempre aponta para um conflito: do menino consigo mesmo, do menino com o pai, entre o menino e os grandes.

Bachelard, ainda, atenta para o fato do tempo expresso no devaneio de in- fância ser profundo em sua concretude e não como simples metáfora. $O$ filósofo afirma que a infância é o poço do ser, o que nos faz lembrar a célebre frase de William Wordsworth: "o menino é o pai do homem”. Relembrar a infância já na idade avançada é entregar-se ao devaneio poético, é querer descer ao poço. Segundo Bachelard,

Quando, no fastígio da idade, no fim da idade, vislumbramos tais devaneios, recuamos um pouco porque reconhecemos que a infância é o poço do ser. Sonhando assim a infância insondável, que é um arquétipo, eu sei que sou tomado por um outro arquétipo. $\mathrm{O}$ poço é um arquétipo, uma das imagens mais graves da alma humana. Essa água negra e longínqua pode marcar uma infância. Ela reflete um rosto espantado. Seu espelho não é o da fonte. Um narciso não se pode comprazer nela. Em sua imagem viva sob a terra, a criança já não se reconhece. [...]. Agora, se uma lembrança de tais reflexos vem numa memória, não será a lembrança de um antemundo? (BACHELARD, 2006, p. 109).

As bases fundadoras do gauche não são tranquilas. Drummond é poeta não só da ironia e do avesso, mas da contradição do existir. Por essa razão, o menino em Boitempo viverá momentos de tensão. É preciso justificar a fala do anjo torto, que disse "Vai, Carlos! ser gauche na vida".

\section{Os animais e a formação do ser}

Estudar as operações simbólicas envolvendo os animais deve começar pela infância, por uma questão levantada por 
Gilbert Durand em suas estruturas antropológicas do imaginário, isto é, a pouca importância dada a essas figurações. Em contrapartida, são os seres que mais povoam nosso imaginário desde idade muito tenra. Assim, Durand destaca:

\begin{abstract}
À primeira vista, o simbolismo animal parece bastante vago porque demasiado comum. Parece que pode agregar valorizações tanto negativas, com os répteis, ratos, pássaros noturnos, como positivas, com a pomba, o cordeiro e, em geral, os animais domésticos. Todavia, apesar dessa dificuldade, qualquer arquetipologia deve abrir com um Bestiário e começar por uma reflexão sobre sua universalidade e banalidade (DURAND, 2002, p. 69).
\end{abstract}

A importância dessas imagens animais reside em sua familiaridade. Uma série de assimilações simbólicas durante a infância faz com que a orientação teriomórfica atinja níveis profundos. $\mathrm{O}$ imaginário é capaz de suplantar o dado empírico, por essa razão:

[...] a salamandra permanece, para a nossa imaginação, ligada ao fogo, a raposa à astúcia, a serpente continua a "picar" contra a opinião do biólogo, o pelicano abre o coração, a cigarra enternece-nos, enquanto o gracioso ratinho repugna-nos (DURAND, 2002, p. 69-70).

Segundo o teórico, alguns povos primitivos (a exemplo dos kurnais, da Austrália) fazem a distinção entre arquétipo imaginário e o animal "objetivo". Nesse tipo de pensamento, o animal surge como um
[...] abstrato espontâneo, objeto de uma assimilação simbólica, como mostra a pluralidade e a universalidade da sua presença tanto numa consciência civilizada como na mentalidade primitiva (DURAND, 2002, p. 70).

De acordo com alguns estudos da linguística comparada, a repartição dos substantivos se deu de forma tardia, sendo pioneira a divisão entre ser animado e inanimado. Para Durand, esses dados indicam a existência de um bestiário na língua, na mentalidade coletiva e também na fantasia individual. Contudo, as características ressaltadas nos animais não dizem respeito à sua animalização, ao contrário, apontam para uma relação com outros objetos ${ }^{3}$.

Não se pode ignorar o fato de que os símbolos teriomórficos reunidos pelo teórico francês introduzem o capítulo sobre o regime diurno (também chamado de postural/heroico). As imagens negativadas da noite e a valorização da elevação e da luz contra a noite negativa estão nele inseridos. Os animais, sob essa perspectiva, associam-se a valores negativos, acentuando sobretudo a angústia da passagem do tempo.

Em princípio, Durand aborda o tema do formigamento, não em sua relação com o movimento das formigas, mas com toda e qualquer agitação de pequenos animais, a qual remete a uma aversão primitiva. Nesse tipo de imaginação, os insetos e vermes transformam-se em larvas, conferindo a esse movimento 
um caráter pejorativo. A repugnância diante da agitação, segundo o autor, se vê racionalizada "na variante do esquema da animação que o arquétipo do caos constitui” (DURAND, 2002, p. 74).

O movimento, assim colocado e relacionado ao caos, isto é, a uma desorganização, liga-se ao medo da mudança. De acordo com Durand:

O esquema da animação acelerada que é a agitação formigante, fervilhante ou caótica parece ser uma projeção assimiladora da angústia diante da mudança, e a adaptação animal não faz mais, com a fuga, que compensar uma mudança brusca por outra mudança brusca. Ora, a mudança e a adaptação e a assimilação que ela motiva é a primeira experiência do tempo (DURAND, 2002, p. 74).

Outro aspecto angustiante acerca da animalidade refere-se ao ato de morder, no qual se centra a passagem do fervilhar ao movimento, até a agressividade:

Muitas vezes, com efeito, no sonho ou na fantasia infantil o animal devorador metamorfoseia-se em justiceiro. Mas, na maior parte dos casos, a animalidade, depois de ter sido símbolo da agitação e da mudança, assume mais simplesmente o simbolismo da agressividade e da crueldade (DURAND, 2002, p. 84).

No que tange à poética de Drummond em Boitempo, ao recuperar o espaço e os elementos naturais, dentre eles os animais, o poeta vence o tempo e assinala o início do gauche. A criação da infância desse personagem é fundamental para sustentar a profecia do anjo torto no "Poema de sete faces".
É nesse aglomerado de afetos que o personagem gauche, pré-poeta, irá se constituir na narrativa da trilogia autobiográfica. Ao retomar a genealogia da família, os detalhes da pequena cidade e suas aventuras de menino, Carlos é capaz de se situar no mundo. Todavia, essa identidade é múltipla e se constrói a partir da relação entre indivíduo e outros seres.

\section{Identidade e animalidade}

Chegamos, finalmente, ao cerne do estudo: as representações animais nos poemas "Signo", "Aquele Andrade" e "Cheiro de couro". Todos estão relacionados a um bestiário específico dentro da construção memorialística do poeta, isto é, o bestiário do âmbito familiar.

Cabe comentar que ao usar o termo bestiário quero expressar o conjunto de animais simbolizados em uma obra; o vocábulo faz referência ao seu texto matriz, surgido na Idade Média. O Bestiário Medieval consistia em um compêndio de animais, organizados de acordo com uma ordem hierárquica e apresentava, na maioria dos casos, uma moralização cristã ao final de cada descrição. $O$ interesse desses manuscritos era estritamente dogmático, não havendo qualquer abordagem de caráter científico em relação aos animais.

Para este estudo, é fundamental encadear essa simbologia fundadora e 
seus ecos na contemporaneidade, pois a função dogmática dos Bestiários se transforma, em nosso tempo, em uma função didática advinda das estratégias poéticas de cada autor. Assim como o gênero da Idade Média almejava transmitir determinado conhecimento, a poesia também serve a esse propósito, ainda que por caminhos indiretos e muito mais abertos à interpretação.

"Signo" encontra-se no capítulo "Um", o sétimo na ordem de Boitempo I. No conjunto de pessoas narradas/recuperadas em sua autobiografia, é vital para o poeta colocar-se como unidade, apesar de suas sete faces na vida adulta. Essa unidade, não menos plural, o destaca dos outros da família, ressalta suas peculiaridades. Ele é um Andrade.

Em "Signo", Drummond se mostra preso ao destino, esse representado pela figura do escorpião, não apenas seu signo zodiacal, mas símbolo de seu temor. A análise permite transcender o valor astrológico do animal, quando o menino tenta negar essa essência dominante. No poema, o homem se põe a dizer coisas ao menino:

Fugias do escorpião

lá no quarto de guardados como quem foge do Cão sem perceber que o trazias desde o primeiro vagido oculto em teu coração (ANDRADE, 2015, p. 525).
O temor causado pelo escorpião é comparado ao medo do Cão, nesse caso, uma alusão ao demônio. Assim como dizer o nome de Deus em vão constitui um pecado, nomear o Demônio configura um ato perigoso por atrair sua presença, daí a substituição por "Cão".

A aversão do menino ao escorpião justifica-se por sua simbologia, em grande parte negativa, e também por ser um animal perigoso no meio natural, em virtude de seu veneno potente. Logo, em "Signo", ligam-se noções do mundo "real" e do meio simbólico (sua acepção astrológica).

Affonso Romano de Sant'Anna, para ilustrar as pulsões de vida e de morte na poética de Drummond, menciona o poema em questão:

O homem nasce sob o Signo da destruição, e num poema com esse sentido, conjugando o fatalismo astrológico, lembrando um fato local e dando um sentido metafísico à imagem, o poeta diz: "Fugias do escorpião/ lá no quarto de guardados/ como quem foge do Cão/ sem perceber que o trazias/ desde o primeiro vagido/ oculto em teu coração" (SANT'ANNA, 2008, p. 159-160).

O "fato local" sublinhado pelo autor, comentado em nota, diz respeito à abundância de escorpiões em Minas Gerais, em especial na região de Belo Horizonte, que causavam um grande número de vítimas anualmente. Dessa forma, conjuga-se o pavor metafísico e o pavor real diante do aracnídeo. 
No contexto dos bestiários medievais, o escorpião aparece como um ser urticante, habitante da terra, e sua singularidade reside no fato de não picar a palma das mãos dos homens. Sua aparição em textos remonta às Metamorfoses, de Ovídio, à História Natural, de Plínio, o Velho, e nas Etimologias, de Isidoro. No bestiário latino traduzido por T.H. White (2015), a entrada sobre o escorpião é bastante sucinta e traz principalmente os aspectos acima comentados. Esses dados, porém, não justificam o temor desmedido de Carlos pelo animal, apenas salientam sua simbologia negativa.

Como signo, o escorpião é o oitavo no horóscopo zodiacal, tem Marte como regente planetário e sua simbologia transita, ao mesmo tempo, entre resistência, fermentação e morte, dinamismo, dureza e lutas. Sobre sua característica sombria, encontramos aporte em Chevalier:

$\mathrm{O}$ animal negro, que foge da luz, vive escondido e é dotado de um ferrão envenenado. Essa reunião compõe um mundo de valores sombrios, próprios para evocar os tormentos e os dramas da vida até o abismo do absurdo, do nada, da morte... Daí o fato de o signo ser colocado sobre a regência de Marte, assim como de Plutão, força misteriosa e inexorável das sombras, do inferno, das trevas interiores (CHEVALIER, 2012, p. 384).

O cenário de conflito interior está de acordo com o quadro da infância complexa de Carlos. Ainda, temos a referência ao momento do nascimento, quando o poeta diz ao si mesmo do passado: "sem perceber que o trazias/ desde o primeiro vagido/ oculto em teu coração". Os momentos da origem de Carlos revelam a afinidade com o diferente, o anormal, nesse caso, o ruim. $\mathrm{O}$ drama vivido no "Poema de sete faces" é recuperado em "Signo" de maneira mais categórica, num jogo de esconde-esconde, em um labirinto do qual é inútil tentar encontrar a saída.

A partir de "Signo", encontramos o escorpião como animal fundador, regente do indivíduo, pois o acompanha desde o primeiro momento de vida até a fase adulta, quando o homem constata o seu destino inescapável:

é ele que te sugere, te comanda, sorrateiro, com seu veneno e ferrão, de tal sorte que, mordido, e mordente, na aflição, de nada valeu, confessa, fugires de escorpião

(ANDRADE, 2015, p. 526).

O único atributo humano dado ao escorpião pelo sujeito do poema é "sorrateiro", exceto isso, temos de entender a negatividade como algo intrínseco ao animal, especialmente no que tange ao veneno e ao ferrão.

Nesse ponto futuro (em relação ao passado do poema), já não se sabe mais a quem o homem dirige seu discurso. Dizer ao menino "confessa" evidencia um tom de escárnio; o adulto parece divertir-se 
com a tentativa em vão do menino de livrar-se de algo seu. Todavia, podemos pensar no escárnio dito pelo adulto para o adulto. $O$ poema, nesse verso específico, carrega uma ambiguidade.

O segundo poema em análise, "Aquele Andrade", remete à figura paterna e está no capítulo "O menino e os grandes", de Boitempo II. No poema, Drummond revela a sua visão infantil sobre o pai em direção a uma temática familiar mais específica. O poema se desenvolve de maneira descritiva, prezando pela distância frequentemente mantida entre poeta-narrador e poeta-pessoa rememorada. Sabemos se tratar do pai não só pelos elementos sublinhando sua importância e sua imponência, mas pela referência a casa.

O animal representado no poema é o cavalo, também ele dotado de algo especial, distinto dos demais:

É o Andrade navegante

pelas roças pelas vinhas

do Pontal?

Em seu cavalo mais alvo singra o mar que não lhe deram.

Viajante mais estranho

deixa a terra

paira alto alto alto

e não chego ao seu estribo

(ANDRADE, 2015, p. 583).

O homem, ao montar o cavalo, desloca-se da terra para o ar e, ao mesmo tempo, para o mar. $\mathrm{O}$ animal transforma-se em seu navio, pois em Minas Gerais não temos o mar senão o imaginado pelo menino. A correspondência entre a nobreza do cavalo e de seu dono não é acidental, pois tal associação era bastante recorrente na Idade Média. Segundo Michel Pastoureau, a sociedade feudal era a sociedade do cavalo, em particular a esfera aristocrática. Nos romances de cavalaria e chansons de geste, eles eram idealizados, ressaltando a forte ligação entre o cavaleiro (ou seu dono) e o animal (PASTOUREAU, 2011).

Porém, como qualquer elemento simbólico, a figuração do cavalo é bastante vasta e múltipla, transitando entre significações positivas e negativas. Os aspectos simbólicos do cavalo vão desde sua representação como animal das trevas e de poderes mágicos, passando pela questão da metamorfose do homem em cavalo (sua característica de divindade das águas) até chegar à sua propriedade de montaria dos deuses, para citar alguns (CHEVALIER, 2012). No poema, entretanto, não há dúvidas da carga positiva depositada na representação desse animal.

A figura do pai é central, enquanto o cavalo é adereço, meio de transporte privilegiado entre os demais. Metamorfoseia-se em um navio, navegando em um mar inexistente no seu aspecto material, mas real em seu atributo imaginário. 
Uma característica, no entanto, percorre "Aquele Andrade": a divergência entre os lugares trilhados pelo pai - da terra passa ao ar e de repente ao mar. Juntamente com a discrepância dos espaços surge a diferença de tamanho. Nesse quesito, precisamos considerar o tamanho real do menino em relação ao de seu pai, um adulto.

Além disso, há o desdobramento imaginário da altura como superioridade. O menino enxerga a altura do pai, a ele inalcançável, com admiração. Sobre os devaneios do grande e do pequeno, Bachelard afirma:

O mundo do devaneio da infância é grande, maior que o mundo oferecido ao devaneio de hoje. Do devaneio poético diante de um grande espetáculo do mundo ao devaneio da infância há um comércio de grandeza. Assim, a infância está na origem das maiores paisagens. Nossas solidões de criança deram-nos as imensidades primitivas (BACHELARD, 2006, p. 96-97).

O cavalo, portanto, não indica apenas status e mudança de local. A partir de sua definição como "cavalo mais alvo", seu atributo positivo é amplificado, considerando a associação do cavalo branco aos símbolos de divindade. Se não houvesse o deslocamento da terra para a montaria no cavalo, o pai continuaria em tamanho real:

Mas desce à porta de casa em tamanho natural

(ANDRADE, 2015, p. 583).
Logo, o poema está centrado na percepção de Carlos a respeito de seu pai e os elementos responsáveis por sua superioridade: o cavalo mais alvo e os mares fazendo o papel da fazenda - único mar possível. O Andrade viaja por entre terras e montanhas, o pai é grande porque a propriedade é grande. Mais do que embarcação de seu pai que singra os mares a ele negados, o cavalo é mudança da altura.

Em Boitempo III, capítulo "O menino e os grandes", temos o último poema desse estudo, "Cheiro de couro", o qual remonta à história familiar, conjugando identidade, animal e memória olfativa.

Nesse exemplar, o boi está metonimizado na imagem do couro e consiste em uma presença frequente, pois é a base da família Andrade. Mesmo estando no capítulo "O menino e os grandes", a voz do poema confunde-se com a do homem rememorante.

$\mathrm{O}$ animal aparece de maneira fragmentada: se dá primeiro pelo odor, dominando todos os espaços, da cidade até o campo. Os objetos compostos por couro, elencados na sequência, apontam apenas para a fragmentação do animal e também para sua morte e sua finalidade. O menino (ou o homem?) se coloca em primeira pessoa, e o poema é fruto do desencadear de memórias pelo cheiro de couro: 
Em casa, na cidade,

vivo o couro

a presença do couro

o couro dos arreios

dos alforjes

das botas

das botinas amarelas

dos únicos tapetes consentidos

sobre o chão de tabuões que são sem dúvida formas imemoriais de couro

(ANDRADE, 2015, p. 668).

A princípio, o boi é cheiro e objetos. Através do olfato, o homem pode ser menino outra vez e reviver experiências como essa. As "formas imemoriais de couro" indicam uma tradição familiar, incalculável na cronologia de Carlos.

Na segunda estrofe, porém, se evidencia a morte, pois, para transformar-se em arreios, alforjes, botas e tapetes, o boi deve ser morto: "Surpreendo, apalpo o cheiro futuro/ dos bois sacrificados/ olhando/ a parada estrutura dos bois vivos" (ANDRADE, 2015, p. 668).

O menino possui um sentido demasiado apurado do cheiro futuro, pois o destino desses animais é imutável. A imobilidade, tanto dos bois sacrificados quanto dos vivos, demonstra uma conformidade na sina de ambos. A estrutura parada dos bois vivos marca-os, de maneira semelhante, para a morte.

O poema abarca, pelo menos, três momentos: um do passado, imemorial, por meio da vivência dos objetos de couro. O menino experimenta o couro a partir do contato com os utensílios. $\mathrm{O}$ couro, na primeira estrofe, é presença material e, em seguida, Carlos vive o couro na experiência olfativa, no "bafo da oficina do seleiro". Ainda na segunda estrofe, o garoto consegue apalpar "o cheiro futuro", pois o sacrifício dos bois sempre se realiza. Na terceira parte, o sujeito avança mais um passo na percepção do futuro:

Aspiro, adivinhando-o

o cheiro do couro nonato

da cria da barriga da vaca Tirolesa

que um dia será carneada

(ANDRADE, 2015, p. 668).

A estrofe expõe uma ambiguidade: quem será carneada um dia, a Tirolesa ou a cria da barriga? Aparentemente, ambas. O destino dos bois é inescapável. É nesse cenário da morte de um animal para a produção de objetos que se pauta a família Andrade, considerando o último verso do poema: "É um cheiro de família, colado aos nomes" (ANDRADE, 2015 , p. 668), no qual entendo "nomes" como substituto de pessoas, membros dessa família.

Dessa maneira, ao contrário dos poemas anteriores, "Cheiro de couro" volta ao tema da essência, familiar, devido à presença constante do boi em todas as suas formas reduzidas e o poder desencadeador da memória através do olfato. 


\section{Expansão filosófica, ética e estética por meio da poesia}

Os três poemas estudados foram do particular (Carlos, menino), passando para um outro particular, familiar (o pai), até chegar à família de modo mais abrangente, a sua identidade marcada pelo odor do couro. Os animais representados possuem diferentes acepções e elas não são acidentais.

Em "Signo", por exemplo, o escorpião, colado ao personagem gauche, carrega simbologia estritamente negativa. Não há espaço para acrescentar a essa imagem sequer um pouco de aspecto positivo. Quando passamos para "Aquele Andrade", a associação entre o pai do menino, cavaleiro montado em seu cavalo, não deixa qualquer dúvida sobre a qualificação positiva do animal. Da mesma forma, em "Cheiro de couro", embora exista todo um cenário de dor, sofrimento e espera, o cheiro é local de fundação de uma família. O boi é representado como propriedade uma das principais dos Andrade - ainda que submetido as mais várias torturas.

Na trilogia em questão, Carlos Drummond de Andrade expande os limites da própria forma do gênero autobiográfico e nos leva a pensar várias questões concernentes ao tratamento conferido aos animais, ainda que seu propósito não fosse pontualmente esse. $\mathrm{O}$ ato de simbolizar o animal é questão filosófica, ética e estética nos poemas analisados.
Sobre a simbolização animal, Maria Esther Maciel faz uma importante observação:

Falar sobre um animal ou assumir sua persona não deixa de ser também um gesto de espelhamento, de identificação com ele. Em outras palavras, o exercício da animalidade que nos habita. Sabe-se que o esforço de entrar no espaço mais intrínseco da vida animal nunca deixou de desafiar poetas e escritores de todos os tempos e tradições. Seja através da sondagem (por vezes erudita) do comportamento e dos traços constitutivos dos bichos de várias espécies, realidades e irrealidades, seja através da encenação de um vínculo afetivo com eles, ou da tentativa de antropomorfizá-los e convertê-los em metáforas do humano, muitos foram e são os autores voltados para a prática do que se nomeia hoje de zooliteratura (MACIEL, 2007, p. 197).

A respeito do conhecido poema "O boi vê os homens", de Claro enigma, a autora sublinha:

Vê-se que a persona bovina de Drummond busca encarnar ou encenar uma subjetividade possível (ainda que inventada), de um ser que, nos confins de si mesmo, é sempre outro em relação ao que julgamos capturar pela força da imaginação. Isso, se considerarmos que todo animal - tomado em sua singularidade, em seu it - sempre escapa às tentativas humanas de apreendê-lo, visto que entre ele e os humanos predomina a ausência de uma linguagem comum, ausência esta que instaura uma distância mútua e uma radical diferença em relação ao outro. No entanto, tal distância/diferença não anula necessariamente aquilo que os aproxima e os coloca em relação também de afinidade. Falar sobre um animal ou assumir sua persona não deixa de ser também um gesto de espelhamento, de identificação com ele. Em outras palavras, o exercício de animalidade que nos habita (MACIEL, 2007, p. 197). 
Os poemas analisados não exemplificam exatamente essa operação de agir no lugar do animal, mas colocam Carlos diante desse outro ser que é parte constituinte fundamental de sua identidade. $\mathrm{O}$ enfrentamento com o escorpião, a admiração pelo pai que se completa pela figura também altiva do cavalo e $o$ cheiro do couro - do boi já fragmentado e transformado em produto, dá ao sujeito possibilidade de compreender seus desafios diante do "mundo, mundo, vasto mundo".

A obra de Drummond comprova ter sido esse espelhamento uma atividade constante no seu exercício poético, dado o número de representações animais. Embora, em alguns casos, o animal cumpra a função de dimensionar o espaço (quando utiliza espécimes pequenos em um local mais amplo), em outros momentos ele aparece como protagonista ou, pelo menos, como um coadjuvante essencial.

A tentativa de compreensão desse outro, que é o animal, por meio do uso do símbolo e da metáfora, possui a mesma intenção dos bestiários medievais: um melhor entendimento dos homens e da humanidade. Dessa forma, bestiário e poesia organizam determinadas imagens de modo a obter/proporcionar um conhecimento sobre algo transcendente.

Pensando especialmente na literatura em campo expandido, mais do que sofrer/propor interferências de outras formas artísticas, permite a reflexão da literatura enquanto registro escrito, colocando à mostra sua fluidez, instabilidade e inespecificidade, muitas vezes; a literatura é o espaço para o desenvolvimento de um pensar específico de um autor. A literatura abre espaço para algo além da exclusividade da imaginação e da ficção e dá lugar a algo real, que dialoga com outras formas de discurso. Tomemos esse excerto de Florencia Garramuño sobre Nove noites, de Bernardo Carvalho:

Um dos romances, talvez não dos mais radicais, que permitem explorar a ideia do campo expansivo é Nove noites: romance (assim reza o título), de Bernardo Carvalho. Proveniente do jornalismo, autor de uma profusa produção de crônicas ao momento de publicar seu primeiro romance, Carvalho exercitava neste texto uma escrita plural que combinava a escrita jornalística, a indefinição autobiográfica, o diário pessoal e o informe antropológico [...] (GARRAMUÑO, 2014, sem paginação).

No caso de Carlos Drummond de Andrade na série Boitempo, a tessitura de uma autobiografia em versos expande, "borra", os limites do conceito de gênero autobiográfico. Rejeita a narração em prosa com uma cronologia bem delimitada e aposta no verso. A pessoa gramatical do discurso transita entre o "ele" e o "tu" e, ainda, o tempo pretérito é usado poucas vezes, comparado ao número de situações presentificadas para o leitor. Somado 
a isso, temos um relato da antiga e contínua exploração do Brasil, de Itabira e de Minas Gerais como um todo. A autobiografia de Drummond, além de todas as subversões que impõe ao conceito de autobiográfico, acaba sendo um documento interessante em diálogo com a história de nosso país.

Ao organizar um bestiário, ainda que disperso, como alicerce de formação de um personagem gauche (mais um desvio do autobiográfico), Drummond propõe uma reflexão do ser humano e sua relação em conflito com os outros animais e a natureza, além de remeter ao gênero matriz Bestiário Medieval, popularizado entre os séculos XII e XIV.

No que tange ao alargamento da literatura, a simbologia animal movimenta questões de estética literária, de composição de poesia, mas vai além: sua existência dentro de um poema aciona nosso conhecimento empírico sobre os animais, nos faz refletir sobre o mundo e o que estamos fazendo dele. Tem assim, portanto, um papel ético dentro da esfera social.

\section{Animals and identity construction in Carlos Drummond de Andrade}

\section{Abstract}

This essay adresses the animal representation as an identity construction in Carlos Drummond de Andrade's memorialistic narrative, namely the Boitempo trilogy. Composed by the works Boitempo, Menino antigo and Esquecer para lembrar, the poet's autobiography ends up subverting the genre in question by proposing a narrative in the form of poetry and also dealing with a well-known character, the gauche. As for the symbolic animal, it is possible to think of it in terms of bestiary, that is, a set of animals that gives the Drummondian universe its own coherence. The study of the poems "Signo", "Aquele Andrade" and "Cheiro de couro", in Boitempo I, II and III, respectively, synthesizes Drummond's journey in bringing together the tips of literature and memory, and thinking of the other who is the animal.

Keywords: Brazilian contemporary poetry; Carlos Drummond de Andrade; Bestiary; Imaginary

\section{Notas}

1 A preferência da idade avançada para a escrita de autobiografias foi destacada por Madeleine Ouellette-Michalska, na conferência intitulada La tentation autobiographique. Ver: SOUZA, Raquel Rolando. Boitempo: a poesia autobiográfica de Drummond. Rio Grande: Editora da FURG, 2002, p. 47.

2 A história anterior ao sujeito é parte (ainda que não seja obrigatório) das narrativas autobiográficas. $\mathrm{O}$ récit de naissance, termo cunhado por Philippe Lejeune, refere-se ao momento 
anterior ao nascimento da pessoa biografada. É uma história, portanto, constituída a partir do relato de terceiros. Ver: SOUZA, Raquel Rolando. Boitempo: a poesia autobiográfica de Drummond. Rio Grande: Editora da FURG, 2002.

3 Durand dá o exemplo da serpente a qual partilha pontos em comum com o grão pelo enterramento e troca de pele e a ascensão e o voo partilhados por pássaro e flecha. Movimentos são mais significativos do que o animal em si. Ver: DURAND, Gilbert. As estruturas antropológicas do imaginário. São Paulo: Martins Fontes, 2002, p. 71.

\section{Referências}

ANDRADE, Carlos Drummond de. Nova reunião: 23 livros de poesia. São Paulo: Companhia das Letras, 2015.

BACHELARD, Gaston. A poética do devaneio. São Paulo: Martins Fontes, 2006.

CHEVALIER, Jean; GHEERBRANT, Alain. Dicionário de símbolos: mitos, sonhos, costumes, gestos, formas, figuras, cores, números. Rio de Janeiro: José Olympio, 2012.

DURAND, Gilbert. As estruturas antropológicas do imaginário. Trad. Helder Godinho. São Paulo: Martins Fontes, 2002.

GARRAMUÑO, Florencia. Frutos estranhos: sobre a inespecificidade na estética contemporânea. Rio de Janeiro: Rocco, 2014. E-book.

PASTOUREAU, Michel. Bestiaires du Moyen Âge. Paris: Seuil, 2011.

SANT'ANNA. Affonso Romano de. Drummond: o gauche no tempo. $5^{\mathrm{a}}$ ed. Rio de Janeiro, Record, 2008.

SOUZA, Raquel Rolando. Boitempo: a poesia autobiográfica de Drummond. Rio Grande: Editora da FURG, 2002.

WHITE.T. H. The book of beasts. New York: Dover Publications, 2015. 